\title{
Secondary Traumatic Stress and Resilience of the Nurses at the Psychiatric Centers in Tehran City, Iran
}

\author{
Ezzat Jafar Jalal ${ }^{1}$, Fahimeh Aziz Mohammadi ${ }^{2}$, Naeimeh Seyyed Fatemi ${ }^{3}$, Hamid Haghani ${ }^{4}$
}

\begin{abstract}
Background \& Aims: Secondary traumatic stress (STS) can be described as an occupational hazard for those providing care to victims of trauma. In health professions, there are times when individuals are in constant and close contact with trauma survivors and experience significant emotional disturbance, thereby becoming indirect trauma victims. Some of STS symptoms include increased negative emotions, the existence of annoying thoughts, failure to separate work from personal life, decreased frustration tolerance, increased anger, depression, disabling and selfish behaviors, fear of working with certain people, self-blame, keeping on one's toes, decreased sense of competence at work, lack of goal, lack of enjoying the profession, decreased performance in unprofessional conditions, and loss of hope in life. Numerous factors such as environmental factors (e.g., work style, perceived organizational support, workload, client needs, and relationships with colleagues) and individual factors (e.g., level of education, level of experience, and coping styles) contribute to STSS. Nurses in psychiatric wards are faced with severe and complicated challenges in the workplace to provide mental health care. In addition, they should be aware of the risk factors and symptoms of STS. Nurses need to skillfully develop resilience in order to cope with occupational problems and ensure their mental health since resilience and the associated behaviors help overcome negative experiences and turn them into positive experiences. The present study aimed to investigate STS and resilience in the nurses at the psychiatric medical centers affiliated to Tehran University of Medical Science in 2018.

Materials \& Methods: This cross-sectional, descriptive study was conducted on 200 nurses working in the psychiatric medical centers affiliated to Iran University of Medical Sciences, Shahid Beheshti University of Medical Sciences, and Tehran University of Medical Sciences. In this regard, Iran Psychiatry Center included $35 \%$ of the total sample size $(n=70)$, whereas Roozbeh Psychiatry Center, Imam Hossein Medical Center, and Rasoul Akram Medical Center encompassed 47\% ( $n=94), 12 \%(n=25)$, and 6\% $(n=11)$ of the total sample size, respectively. Data were collected using an STS scale and resilience questionnaire. The research objectives and methods of filling the questionnaires were explained to the participants, and each questionnaire was completed within 20-30 minutes. Sampling was carried out from August to November 2018. Moreover, data analysis was performed in SPSS version 16 using descriptive statistics (mean, standard deviation, frequency, and frequency percentage), independent t-test, analysis of variance, and Mann-Whitney $U$ in order to determine the relationship between demographic characteristics and STS and resilience.

Results: In this study, most nurses (81\%) were female, and the mean age of the participants was $36.69 \pm 8.01$ years. Moreover, more than half of the subjects $(57 \%)$ were married. Regarding the level of education, most nurses $(83.5 \%)$ had a BSc. In terms of employment status, $38 \%$ of the subjects had permanent employment, which had the highest frequency, compared to other levels. Furthermore, the mean work experience of nurses was $11.28 \pm$

\footnotetext{
1. Lecturer, Department of Nursing Management, School of Nursing and Midwifery, Iran University of Medical Sciences, Tehran, Iran

${ }^{2}$. MS in Psychiatric Nursing, School of Nursing and Midwifery, Iran University of Medical Sciences, Tehran, Iran (Corresponding author) Tel: 09124488466 Tmail: azizmohammadi.f@ tak.iums.ac.ir

3. Professor, Nursing Care Research Center, Department of Psychiatric Nursing, School of Nursing and Midwifery, Iran University of Medical Sciences, Tehran, Iran

4. Instructor, Department of Biostatistics, School of Health, Iran University of Medical Sciences, Tehran, Iran
} 
7.22 years. On the other hand, the average experience of working in the ward was $4.9 \pm 4.21$ years. More than half of the subjects $(58.5 \%)$ were clinical nurses, and the mean working hours of nurses was $173.99 \pm 28.43$. Most nurses in this study $(74.5 \%)$ reported moderate economic status, and three-quarters of them had liability insurance. On average, the ratio of nurse to the patient was $9.63 \pm 3.03$ in the morning, $11.67 \pm 4.29$ in the evening, and $12.25 \pm 4.31$ in the evening. In total, $30 \%, 21.5 \%$, and $26 \%$ of the nurses reported high and severe, moderate, and mild secondary traumatic stress, respectively. Furthermore, the mean score of STS and resilience was $37.64 \pm$ 10.03 and $69.71 \pm 13.63$, respectively. According to the results, there was a significant but reverse correlation between resilience and STS, meaning that those with higher STS had lower resilience $(r=-0.513, P \leq 0.001)$.

Conclusion: According to the results, the mean score of STS was moderate in the nurses, while the mean score of resilience was above the median of the questionnaire. According to the results, there was a significant relationship between STS and resilience of psychiatry nurses as a dimension of psychological health. In addition, there was a considerable association between psychological health and resilience. Nurses in the psychiatric ward are at greater risk of experiencing stress because they work in direct contact with clients with mental disorders in highly stressful and difficult conditions in psychiatric hospitals. In this study, more than $50 \%$ of nurses working in psychiatric wards reported symptoms of STS. Reporting this experience of the population will help support nurses' mental health by promoting awareness and training programs. Moreover, it may prevent their turnover due to work-related stress. Suggestions for preventing and treating STS include strategies such as reducing workload, increasing staff supervision, improving staff support, increasing staff leisure and providing opportunities for nurses to receive mental health services. The resilience of nurses working in psychiatric wards can also be improved by managing their physical and mental stress and promoting their mental health.

Keywords: Secondary Traumatic Stress, Resilience, Nurses, Psychiatric Ward

\section{Conflict of Interest: No}

How to Cite: Jafar Jalal E, Aziz Mohammadi F, Seyyed Fatemi N, Haghani H. Secondary Traumatic Stress and Resilience of the Nurses at the Psychiatric Centers in Tehran City, Iran. Iran Journal of Nursing. 2019; 32(120):36-49.

Received: 19 Jul 2019

Accepted: 12 Oct 2019 


\title{
استرس ثانويه ناشى از آسيب و تاب آورى در برستاران بخشهاى روانيزشكى شهر تهران
}

\author{
عزت جعفر جلال '، فهيمه عزيزمحمدى '، نعيمه سيد فاطمى"، حميد حقانىع
}

جكيده

زمينه و اهداف: استرس ثانويه ناشى از آسيب را مىتوان به شكل يك خطر شغلى براى افرادى كه مراقبت مستقيم از قربانيان آسيب را به عهده دارند

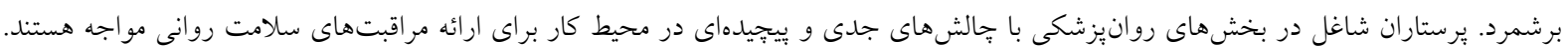

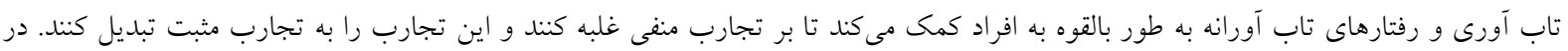

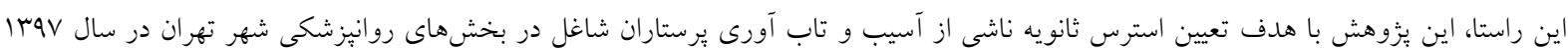
انجام شد.

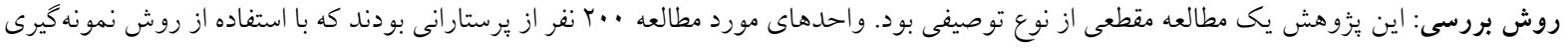

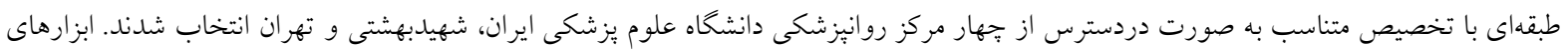

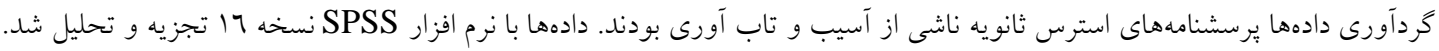

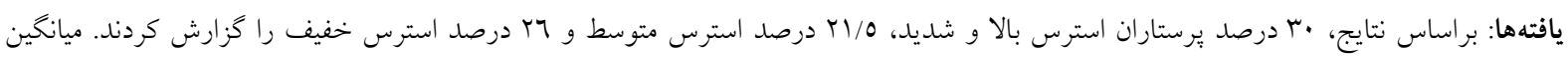

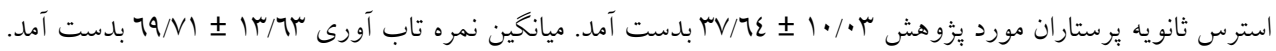

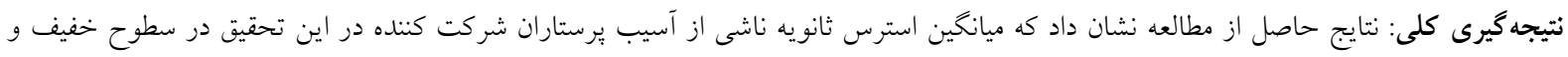

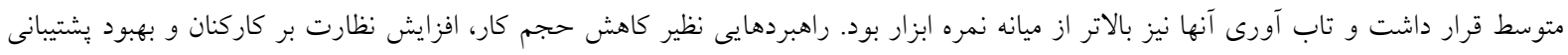

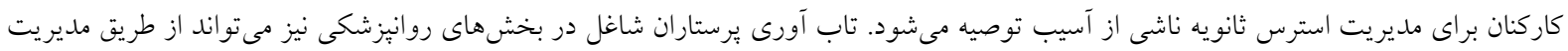
استرس جسمى و روانى آنها و ارتقاى سلامت روانى آنها ارتقاء يابد.

كليدوازهها: استرس ثانويه ناشى ازآسيب، تاب آورى، يرستاران، بخش روانيزشكى

تعارض منافع : ندارد

تاريخ دريافت: 91/2/19

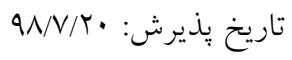

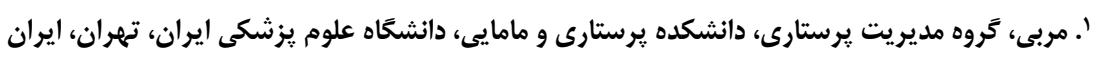

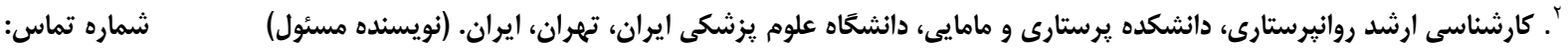
Email: azizmohammadi.f@ tak.iums.ac.ir

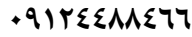

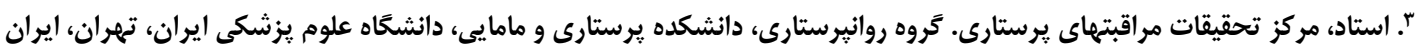

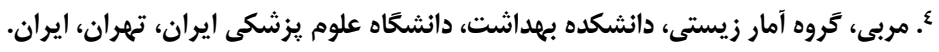


در معرض خطر ابتلا به سندرم استرس ثانويه ناشى از

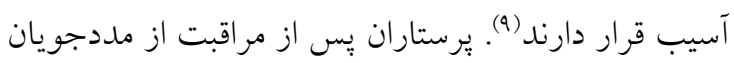

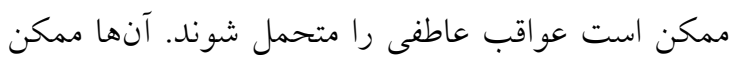

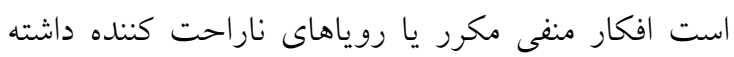

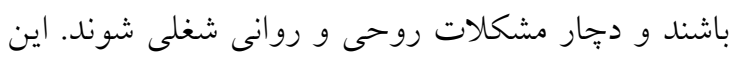
تجربيات ممكن است منجر به ترك شغل يرستاران

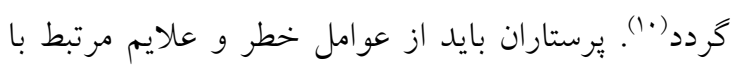

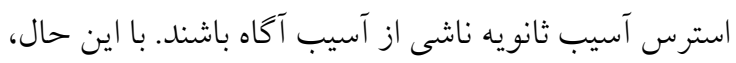

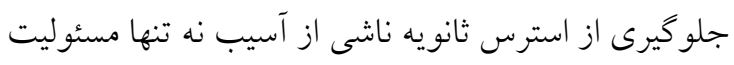

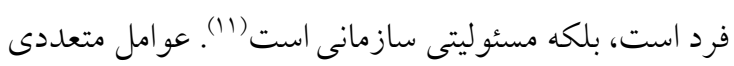

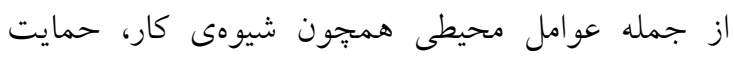
سازمانى درى شده، حجم كار، نيازهاى مددجويان، و

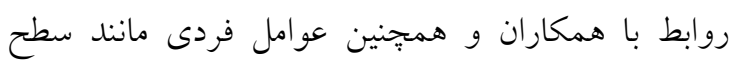
تحصيلات، ميزان تجربه و سبكهاى مقابله با استرس در فر فردئ

$$
\text { توسعه STSS نقش دارند Ir'). }
$$

با وجود تمام اين خالشها، تاب آورى برستاران را قادر

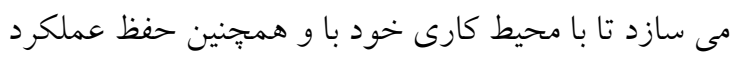

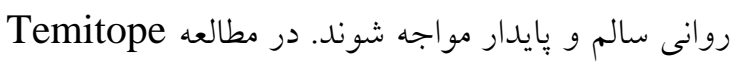
همبستخى منفى معنى دارى بين تاب آورى و استرس ثانويه

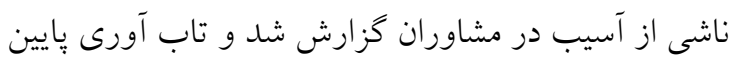

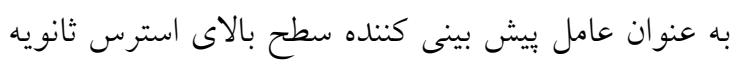

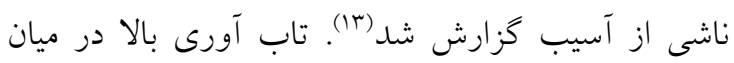

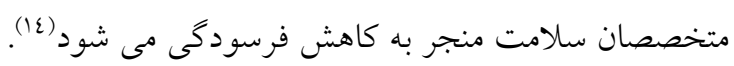

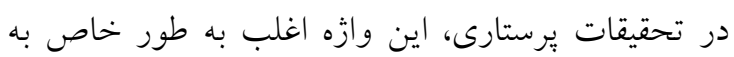
جالشهاى حرفهاى كه يُرستاران تجربه مى كنند، مربوط مىشود و به عنوان يك ظرفيت شخصى تلقى مى شود كه

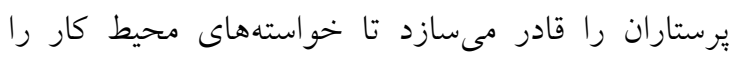

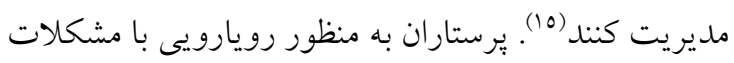
حرفهاى و تأمين سلامت روانى خود بايد به طور ماهرانه

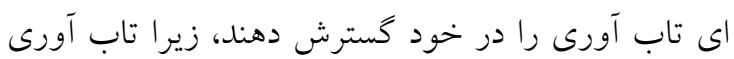
و رفتارهاى تاب آورانه به طور بالقوه به افراد كمك مى كند تا بر تجارب منفى غلبه كند و اين تجارب را به تجارب

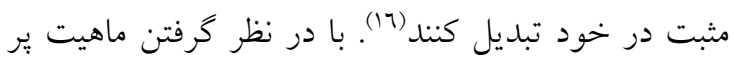

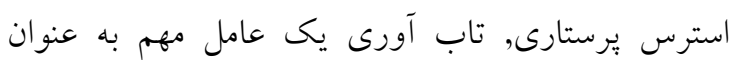

\section{مقدمه}

امروزه بِرستاران با افزايش استرسهاى ناشى از كار مواجه

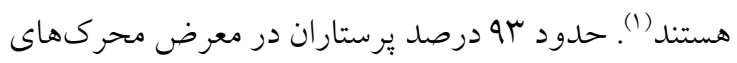

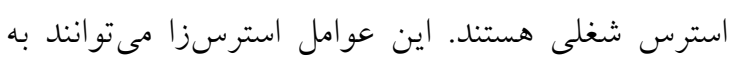

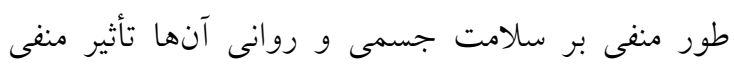

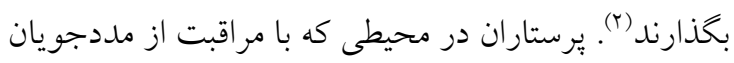

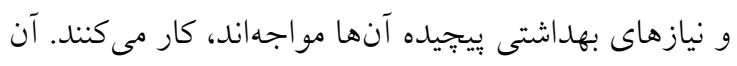

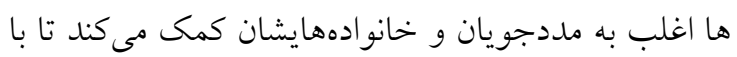

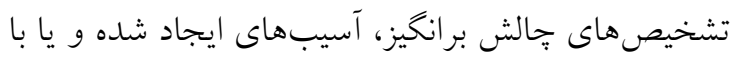

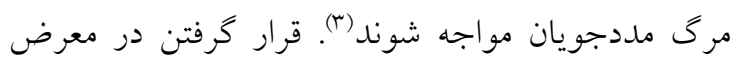

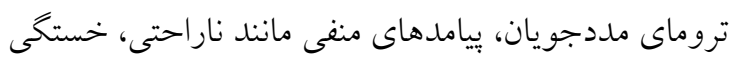
عميق و ييامدهاى منفى عاطفى مانند استرس ثانويه ناشى

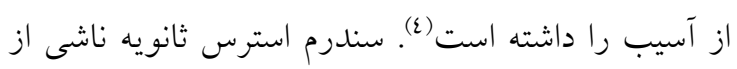

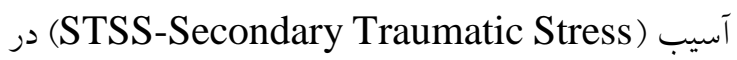
حرفههاى بهداشتى زمانى ايجاد مى شود كه افراد در

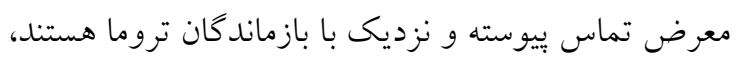

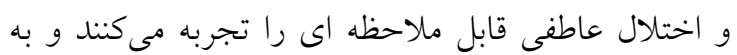

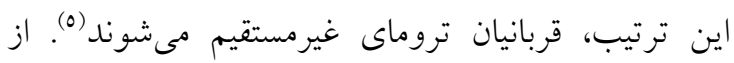
علايم استرس ثانويه ناشى از آسيب، مئى توان افزيش ايش هيجان

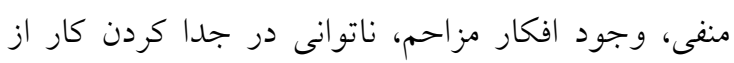

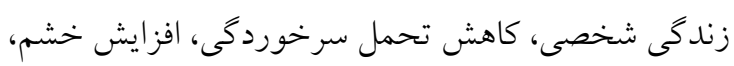

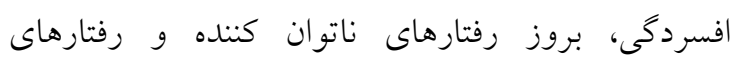

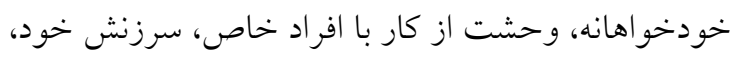
كوش به زنغىى، كاهش احساس شايستكى در كار، نداشتن

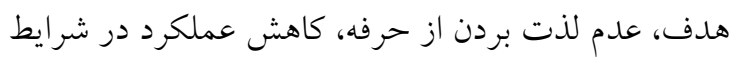

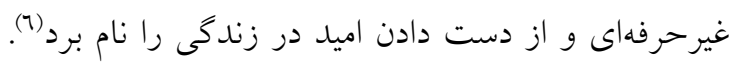

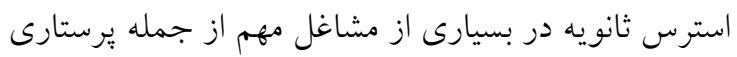
كزارش شده است و ممكن است باعث شود كه يرستاران

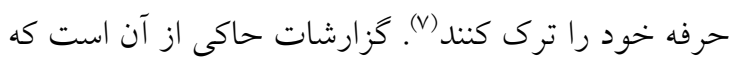

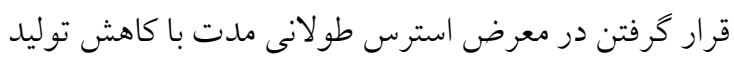
نوروتروفيك مغزى همراه است. اين وضعيت باعث

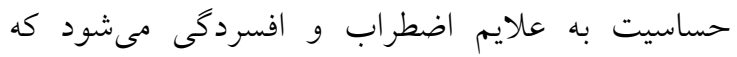

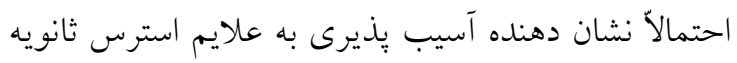

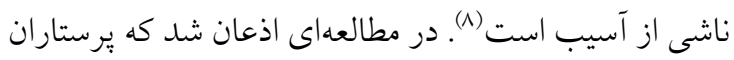


دسترس انتخاب شدند. مركز آموزشى درمانى روانيزشكى

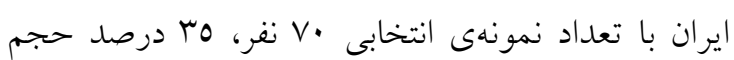

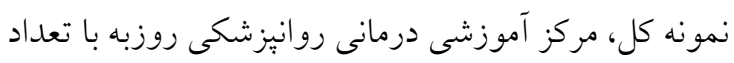

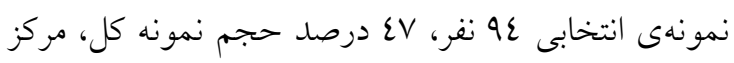

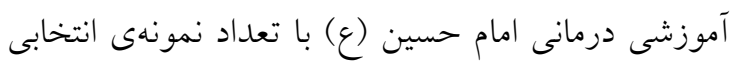

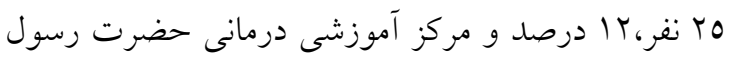

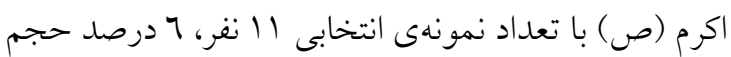
نمونه كل را در بركرفتهاند.

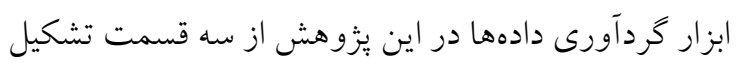
شد: قسمت اول مشخصات فردى واحدهاى يزوهش را ران مورد بررسى قرار مىداد. قسمت دوم شامل يرسشنامه

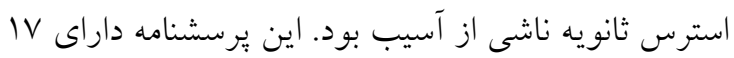

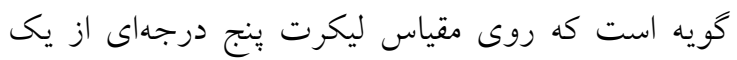

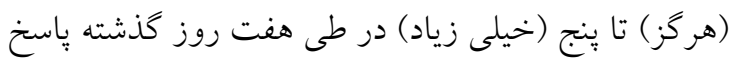
داده مىشود. استرس ثانويه ناشى از آسيب سه خرده مقياس لهر

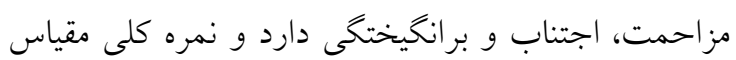

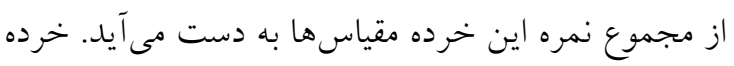

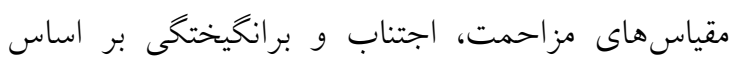

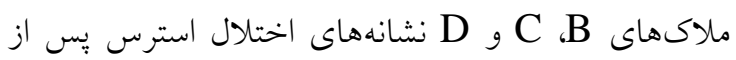
Post-traumatic stress disorder (PTSD سانحه در DSM-IV تنظيم شدهاند. هر يك از عبارات اين

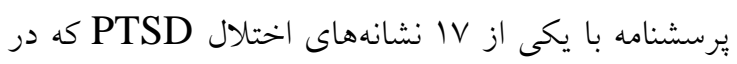

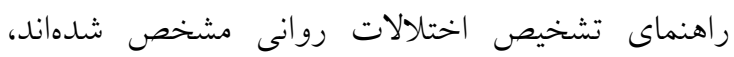

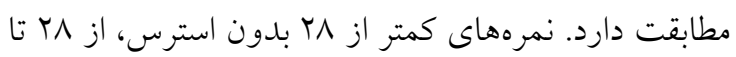

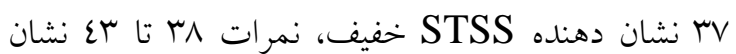
دهنده STSS متوسط است، نمرات بين عـ تا دئ نشان

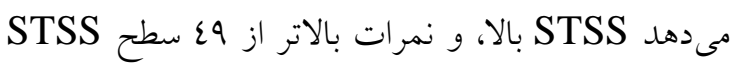

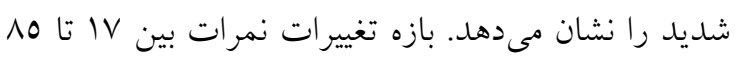

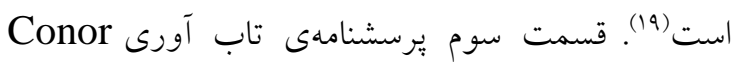
and Davidson هميشه نادرست تا هميشه درست (از صفر تا ع) داراى كويه است. اين يرسشنامه بينج عامل شايستخى/استحكام

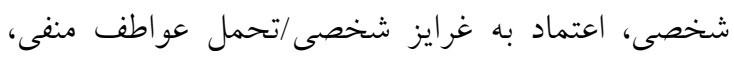

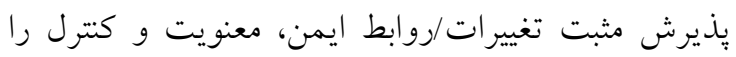

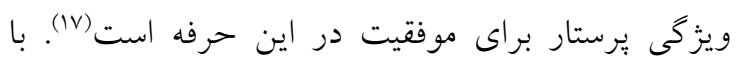
وجود افزايش مطالعات اخير در مورد استرس ثانويه ناشى برسي از آسيب در بخشهاى مختلف، مطالعات اندكى در مورد

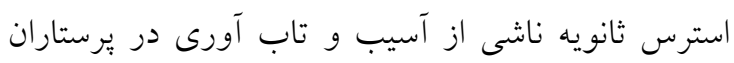
شاغل در بخشهاى روانيزشكى وجود دارد. در همين رابطه تابله

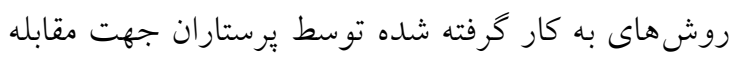

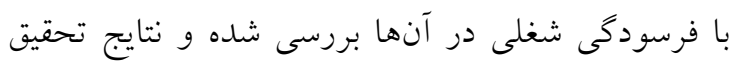

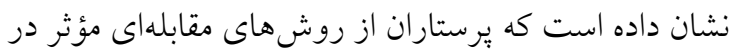
اين جهت سود نبردهاند و در معرض استرس بالا قرار

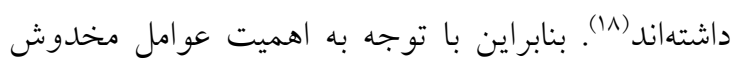
كننده سلامت روان يرستاران، اين مطالعه با هدف تعيين

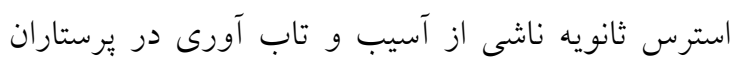
شاغل در بخشهاى روانيزشكى مراكز آموزشى درمانى دانشكاههاى علوم يزشكى شهر تهران انجام شد.

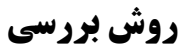

اين يزوهش يكى مطالعه مقطعى از نوع توصيفى بود كه در

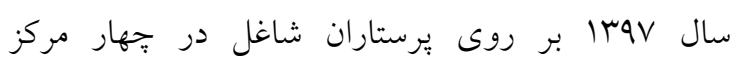

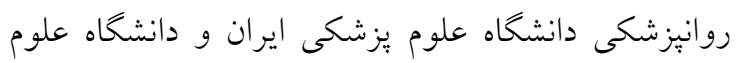

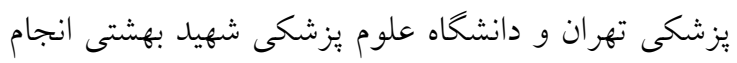

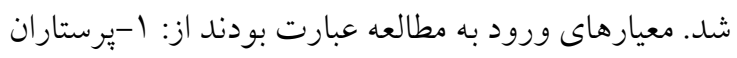

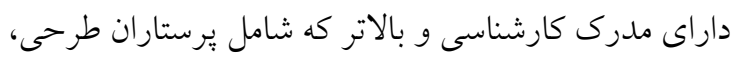

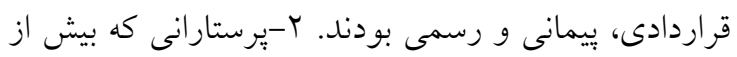

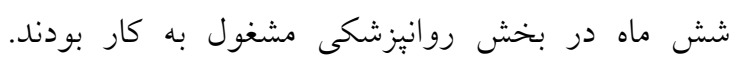

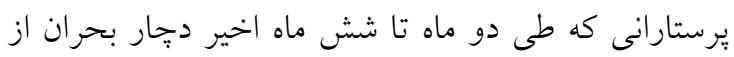

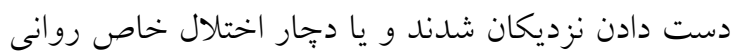
بودند از مطالعه خارج شدند. حجم نمونه بر اساس

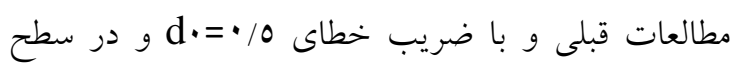

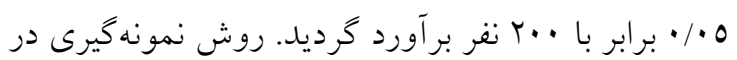

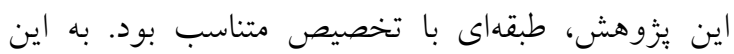
ترتيب كه ابتدا ليست بيمارستانهاى واجد شرايط مطالعه

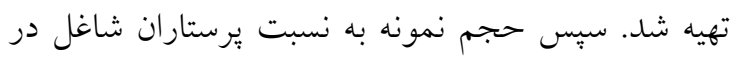

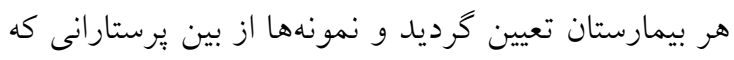

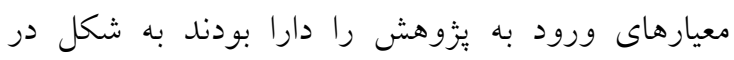


استرس ثانويه ناشى از آسيب و تاب آورى، آزمونهاى تى

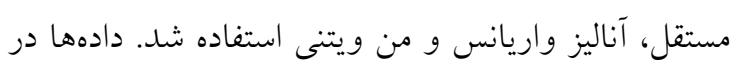

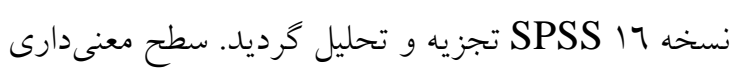

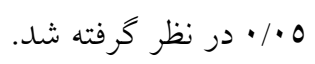

\section{يافتهها}

طبق يافتهاى مشخصات جمعيت شناختى، بيشتر يرستار ان

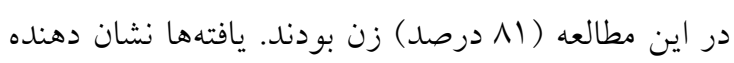

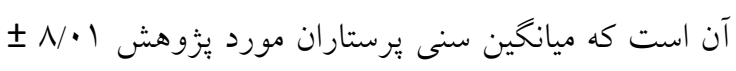

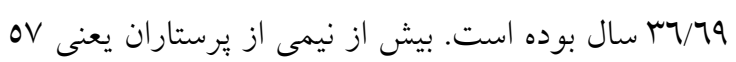

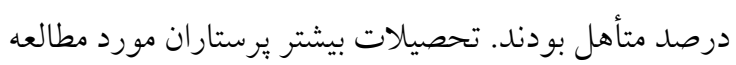

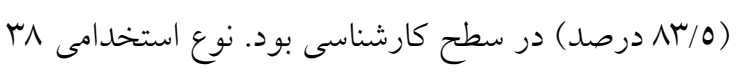

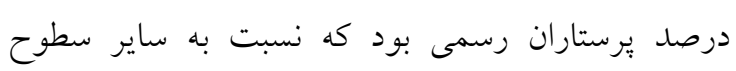

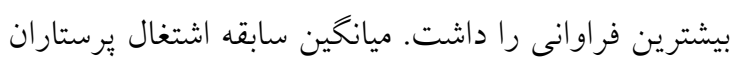

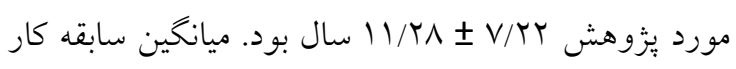

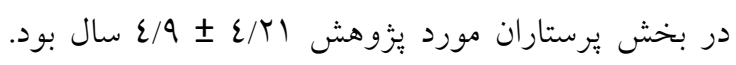

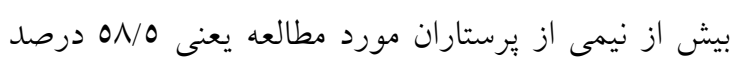

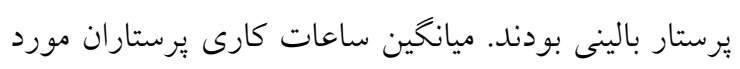

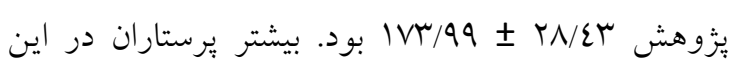

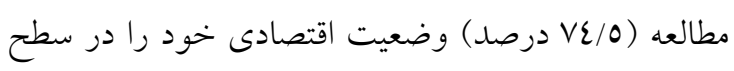

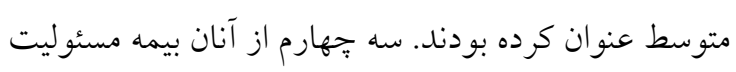

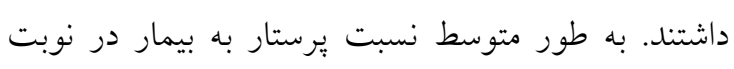

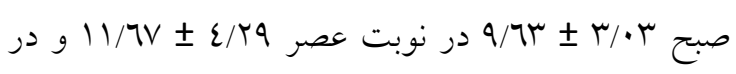

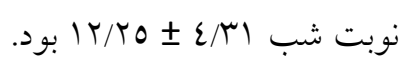

جدول شماره ا: فراوانى و درصد برستاران داراى استرس ثانويه

\begin{tabular}{|c|c|c|}
\hline درصد & فراوانى & استرس ثانويه \\
\hline$T Y / O$ & ¿o & بدون استرس بYر> \\
\hline r & or & خفيف rN-rV \\
\hline rI/O & $\varepsilon r$ & 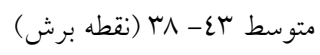 \\
\hline 10 & $r$. & بالا \\
\hline 10 & r. & خديد \\
\hline $1 \cdots$ & $r \cdot \cdot$ & جمع \\
\hline \multicolumn{2}{|c|}{$r V / \neg \varepsilon \pm 1 \cdot / \cdot r$} & انحرف معيار 土 ميانخين \\
\hline \multicolumn{2}{|c|}{$|\wedge-7|$} & بيشينه-كمينه \\
\hline
\end{tabular}

شامل مىشود. دامنه تغييرات نمره كل در اين برسشنامه از

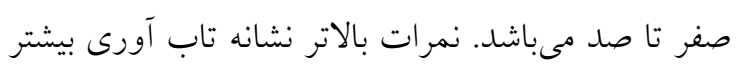
خواهند بود (r.).

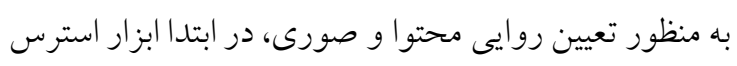

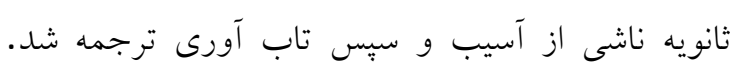

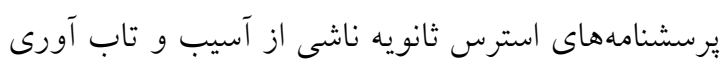
جهت بررسى روايى صورى و روايى محتوا در اختيار ينج

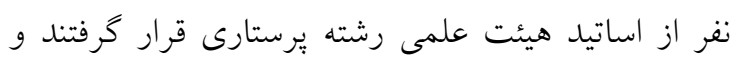

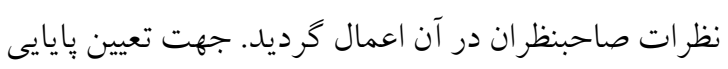
يرسشنامه از روش همسانى درونى به وسيله محاسبه

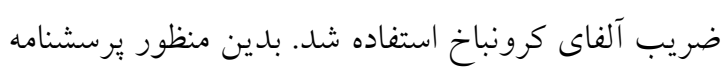

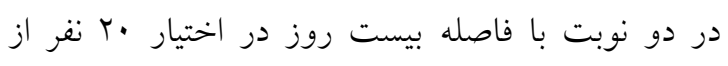

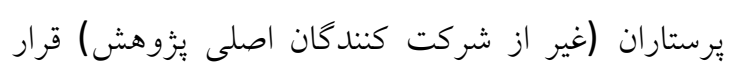
كرفت. ضريب آلفاى كرونباخ به دست آمده بر ایى يرسشنامه

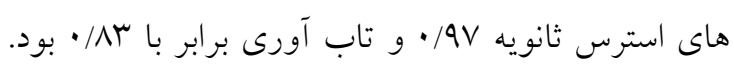

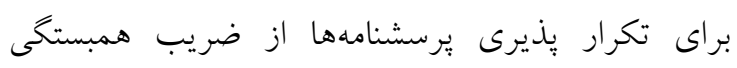

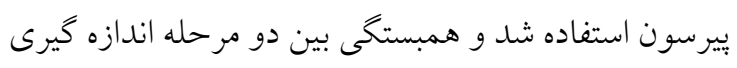

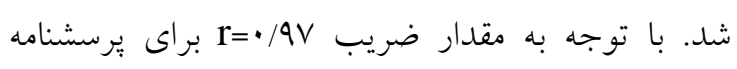

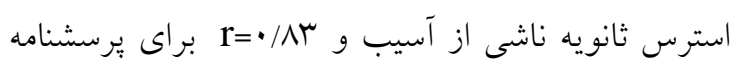

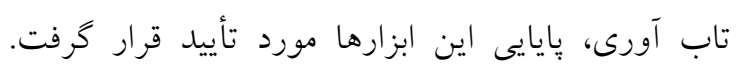
يزوهشخر يس از كسب مجوز كميته اخلاق دانشخاه علوم

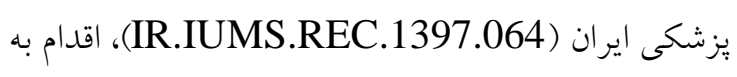

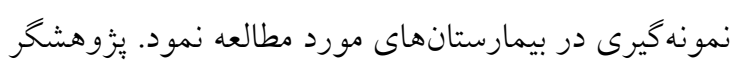

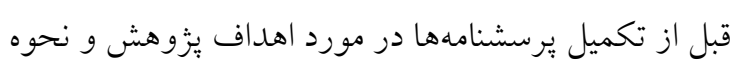

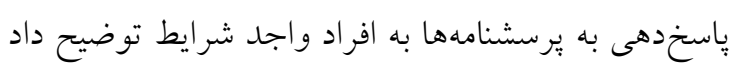

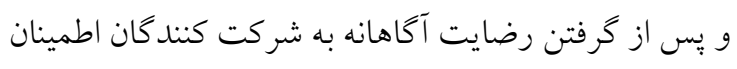

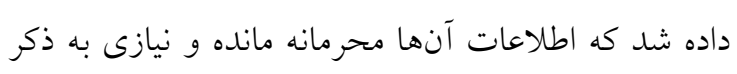

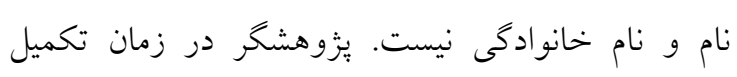

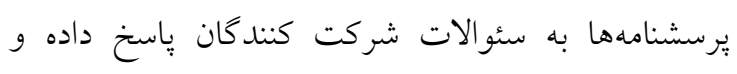

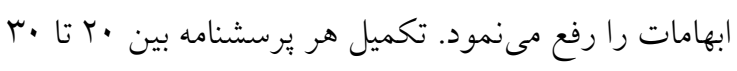

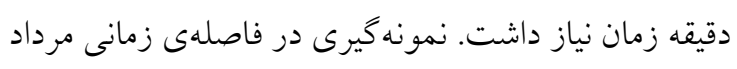

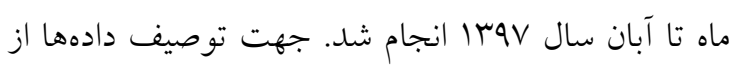

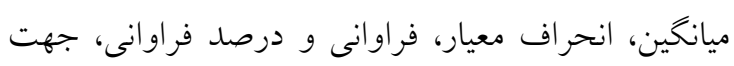
تعيين ارتباط بين مشخصات جمعيت شناختى و و 
يافتهاى اين مطالعه (جدول شماره () نشان داد كه . درصد بِرستاران روانيزشكى دجّار استرس شديد بودند و

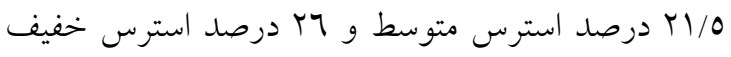
داشتند.
نوبت كارى بيشتر برستاران (VN درصد) به صورت گردشى بود. سه جهارم از يرستاران مورد يزوهش اعلام كردند كه

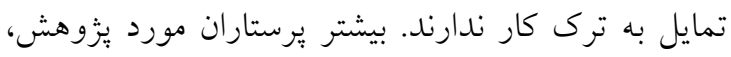
سابقه شركت در كار گاه مديريت استرس را نداشتند.

جدول شماره ז: شاخصهاى عددى استرس ثانويه و ابعاد آن در يرستاران مورد يزوهش

\begin{tabular}{|c|c|c|c|c|c|c|c|c|}
\hline \multicolumn{4}{|c|}{ مبناى ا تا ه } & \multirow{2}{*}{ انحراف } & \multirow[t]{2}{*}{ ميانخين } & \multirow[t]{2}{*}{ بيشينه } & \multirow[t]{2}{*}{ كمينه } & \multirow{2}{*}{ استرس ثانويه و حيطه هاى } \\
\hline انحر اف معيار & ميانكين & بيشينه & كمينه & & & & & \\
\hline.$/ 70$ & $T / l$ & $\varepsilon / r$ & 1 & $r / r o$ & $1 \cdot 10 r$ & rI & 0 & مزاحمت \\
\hline$\cdot / 7 \varepsilon$ & $r / T 1$ & $r / v 1$ & 1 & $\varepsilon / 0 r$ & $10 / 27$ & r & v & اجتناب \\
\hline$\cdot / 7 V$ & T/M & $r / \Lambda$ & 1 & $r / \mu V$ & $11 / 77$ & 19 & 0 & برانخيختخى \\
\hline .109 & $r / T)$ & $r / 09$ & $1 / \cdot 7$ & $1 \cdot / \cdot r$ & $r V / T \varepsilon$ & 71 & 11 & استرس \\
\hline
\end{tabular}

ميانگين سر/ץ بالاترين ميانگين نمره را در بين ساير حيطه ها كسب كرده است (جدول شماره r).

همجِنين نتايج نشان داد كه ميانخين نمره تاب آورى سر/ I9/VI I به دست آمله كه از ميانه نمره ابزار يعنى •0 بالاتر است (جدول شماره ب؟).

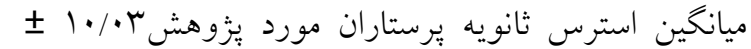
ع آ به دست آمد. بنابراين ميانخين استرس ثانويه ناشى از آسيب يرستاران شركت كننده در يُزوهش حاضردر بين سطوح خفيف و متوسط قرار داشت. يافتهاى اين مطالعه نشان دهنده آن است كه استرس در حيطه برانخيختخى با

جدول شماره سا: شاخصهاى عددى تاب آورى و ابعاد آن در يرستاران مورد يزوهش

\begin{tabular}{|c|c|c|c|c|c|c|c|c|}
\hline \multicolumn{4}{|c|}{ مبناى · تا ع } & \multirow{2}{*}{ معيار } & \multirow[t]{2}{*}{ ميانگين } & \multirow[t]{2}{*}{ 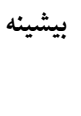 } & \multirow[t]{2}{*}{ كمينه } & \multirow[t]{2}{*}{ تاب آورى } \\
\hline انحراف معيار & 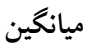 & بيشينه & كمينه & & & & & \\
\hline$\cdot / 7 r$ & $r / \Lambda 1$ & $\varepsilon$ & 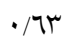 & $\varepsilon / 99$ & $r Y / 0 \varepsilon$ & rt & 0 & شايستخى / استحكام شخصى \\
\hline$\cdot / 71$ & $r / T V$ & $\varepsilon$ & $\cdot / 1 \varepsilon$ & $\varepsilon / \pi$ & $1 \Lambda /{ }^{\prime}$ & r^ & 1 & اعتماد به غرايز شخصى /تحمل عواطف منفى \\
\hline . 104 & r/AO & $\varepsilon$ & $1 / \varepsilon$ & $r / 79$ & $1 \varepsilon / T_{0}$ & $r \cdot$ & V & يذيرش مثبت تغييرات/روابط ايمن \\
\hline$\cdot / \mathrm{VI}$ & $r / \Lambda r$ & $\varepsilon$ & 1 & $r / 10$ & N/01 & ir & r & 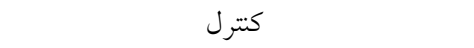 \\
\hline$\cdot / 17$ & $r / \wedge \varepsilon$ & $\varepsilon$ & • & $1 / N \mu$ & $0 / 79$ & $\wedge$ & · & 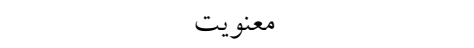 \\
\hline$\cdot / 0 \varepsilon$ & T/VA & $\varepsilon$ & $\cdot / 97$ & 1r/7r & $79 / 11$ & $1 \cdots$ & $r \varepsilon$ & تاب آورى \\
\hline
\end{tabular}

ترى كار داشتند، بيشتر بوده است. نتيجه مقايسه دو به دو نشان دهنده آن بود كه استرس يرستارانى كه وضعيت اقتصادى ضعيفى داشتند به طور معنى دارى بالاتر از سطح

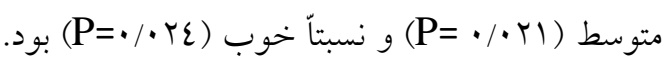

نتايج تحليل هاى آمارى در جدول شماره ع نشان داد كه وضعيت اقتصادى (ع)/ (P=•) و تمايل به ترى كار (P = با استرس ثانويه ارتباط معنى دار آمارى داشته است و ميانخين نمره كسب شده در برستارانى كه تمايل به 


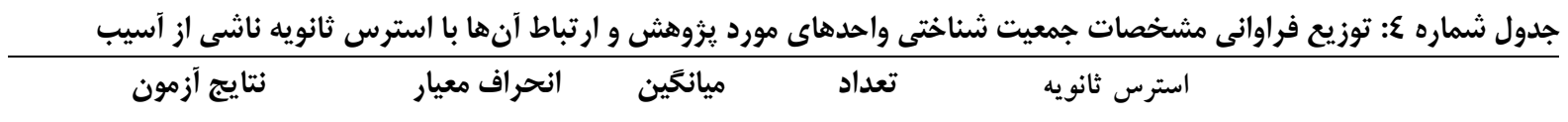

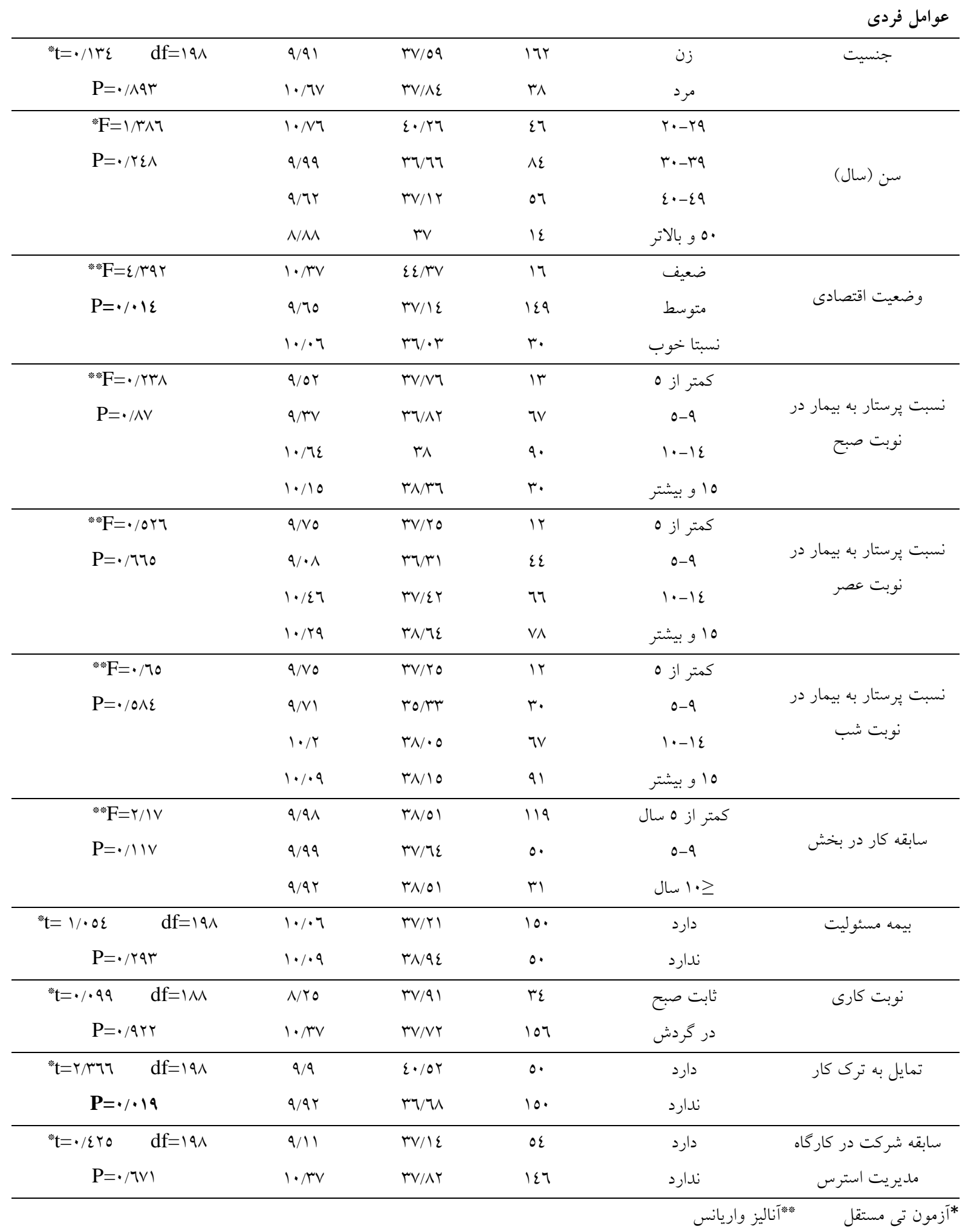

بر ستارانى كه نوبت كارى در كردش داشتند، به طور معنى

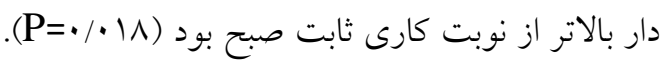

همجنين براساس يافتهها در جدول شماره 0، نوبت كارى

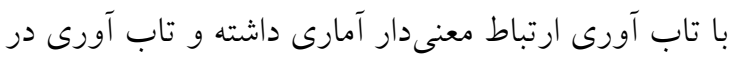


يافتها (جدول شماره 7) نشاندهنده آن است كه تاب افرادى كه استرس ثانويه ناشى از آسيب بالاترى دارند از

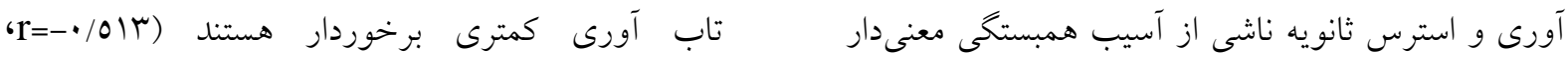

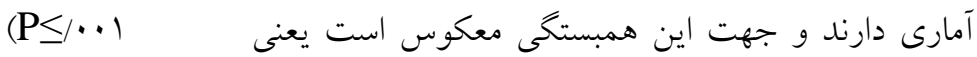
جدول شماره 0: توزيع فراوانى مشخصات جمعيت شناختى واحدهاى مورد يزوهش و ارتباط آنها با تاب آورى يرستاران

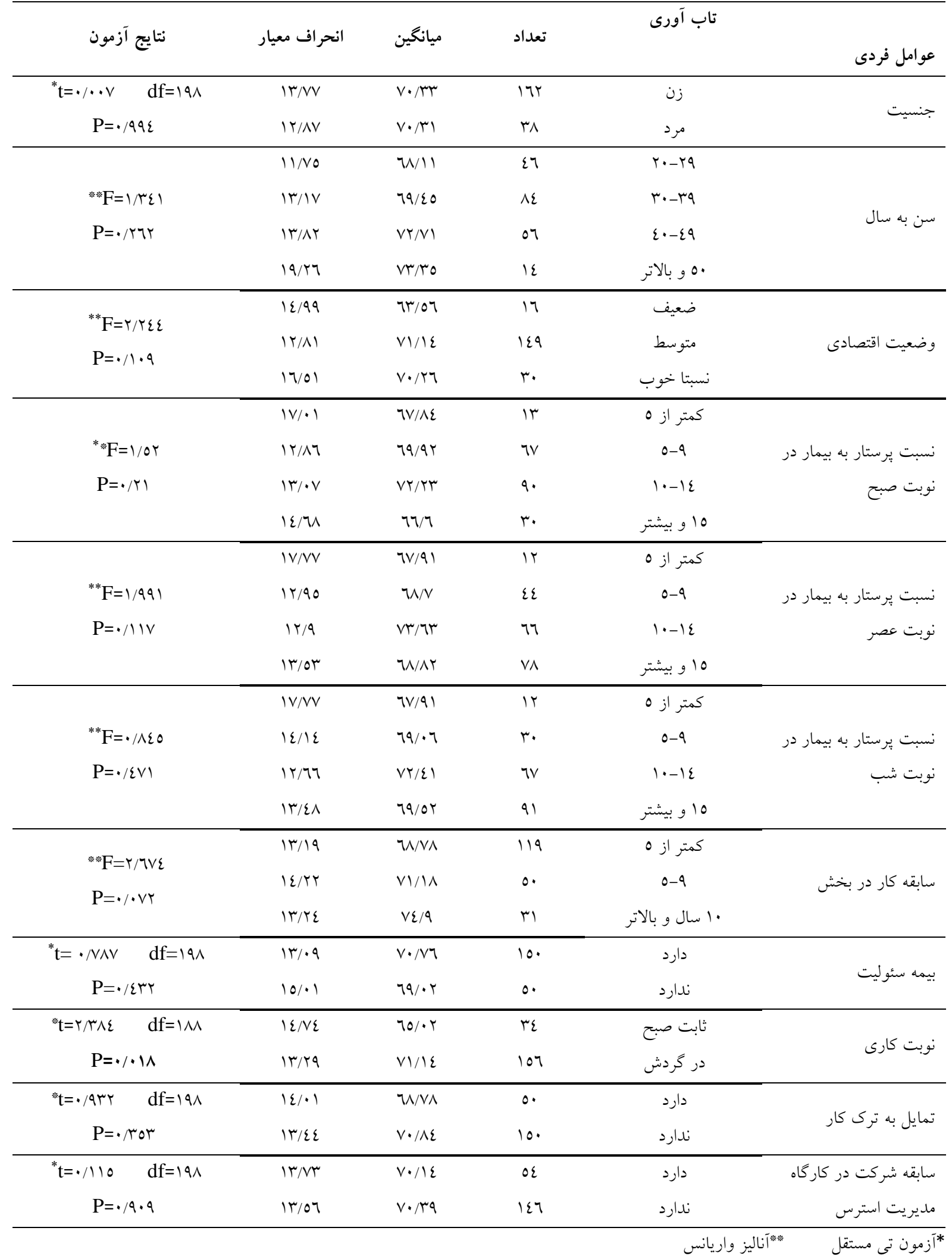




\begin{tabular}{|c|c|c|c|c|}
\hline \multicolumn{4}{|c|}{ نويه و حيطههاي آن } & \multirow[t]{2}{*}{ تاب آورى و حيطههاى آن } \\
\hline 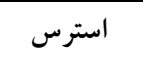 & برانگيختخى & 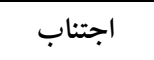 & 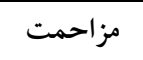 & \\
\hline $\mathrm{r}=-\cdot / \varepsilon \wedge \Lambda$ & $\mathrm{r}=-\cdot / \varepsilon \mathrm{VV}$ & $\mathrm{r}=-\cdot / \varepsilon 0 \varepsilon$ & $\mathrm{r}=-\cdot \mu \mathrm{VV}$ & \multirow{2}{*}{ شايستخى / استحكام شخصى } \\
\hline $\mathrm{P}<\cdot / \cdot \cdot \cdot$ & $\mathrm{P}<\cdot / \cdot \cdot 1$ & $\mathrm{P}<\cdot / \cdot \cdot 1$ & $\mathrm{P}<\cdot / \cdot \cdot 1$ & \\
\hline $\mathrm{r}=-\cdot /\{7 \mid$ & $\mathrm{r}=-\cdot / 209$ & $\mathrm{r}=-\cdot / 217$ & $\mathrm{r}=-\cdot / \mathrm{rro}$ & \multirow{2}{*}{$\begin{array}{c}\text { اعتماد به غرايز شخصى/ تحمل عواطف منفى } \\
\text { عنى }\end{array}$} \\
\hline $\mathrm{P}<\cdot / \cdot \cdot 1$ & $\mathrm{P}<\cdot / \cdots+1$ & $\mathrm{P}<\cdot / \cdots 1$ & $\mathrm{P}<\cdot / \cdot \cdot 1$ & \\
\hline $\mathrm{r}=-\cdot / 2 \uparrow \wedge$ & $\mathrm{r}=-\cdot / \varepsilon \varepsilon 1$ & $\mathrm{r}=-\cdot / \varepsilon \cdot 0$ & $\mathrm{r}=-\cdot / \mu$ & \multirow{2}{*}{ يذيرش مثبت تغييرات/ روابط ايمن } \\
\hline $\mathrm{P}<\cdot / \cdot \cdot 1$ & $\mathrm{P}<\cdot / \cdots+1$ & $\mathrm{P}<\cdot / \cdots 1$ & $\mathrm{P}<\cdot / \cdots 1$ & \\
\hline $\mathrm{r}=-\cdot / \mu q \mathrm{~V}$ & $\mathrm{r}=-\cdot / \mu \wedge \mu$ & $\mathrm{r}=-\cdot / \mu \wedge \mu$ & $\mathrm{r}=-\cdot / r 9 r$ & \multirow[t]{2}{*}{ كترل } \\
\hline $\mathrm{P}<\cdot / \cdots 1$ & $\mathrm{P}<\cdot / \cdots 1$ & $\mathrm{P}<\cdot / \cdot \cdot 1$ & $\mathrm{P}<\cdot / \cdot \cdot 1$ & \\
\hline $\mathrm{r}=-\cdot / \mu / r$ & $\mathrm{r}=-\cdot / \mu \cdot 1$ & $\mathrm{r}=-\cdot / \mu \mathrm{r}$ & $\mathrm{r}=-\cdot / \mathrm{r}$ & \multirow[t]{2}{*}{ معنويت } \\
\hline $\mathrm{P}<\cdot / \cdots 1$ & $\mathrm{P}<\cdot / \cdots 1$ & $\mathrm{P}<\cdot / \cdots 1$ & $\mathrm{P}<\cdot / \cdots 1$ & \\
\hline $\mathrm{r}=-\cdot / 01 \mathrm{r}$ & $\mathrm{r}=-\cdot \cdot 10 \cdot 7$ & $\mathrm{r}=-\cdot / \varepsilon \wedge 1$ & $\mathrm{r}=-\cdot / \mu \uparrow$ & \multirow{2}{*}{ 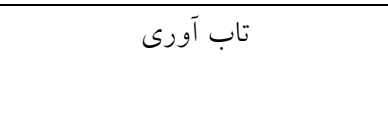 } \\
\hline $\mathrm{P}<\cdot / \cdot \cdot 1$ & $\mathrm{P}<\cdot / \cdot \cdot \mid$ & $\mathrm{P}<\cdot / \cdot \cdot \mid$ & $\mathrm{P}<\cdot / \cdot \cdot \mid$ & \\
\hline
\end{tabular}

از آسيب را گزارش كرده بودند (r). در مطالعهى Kellogg

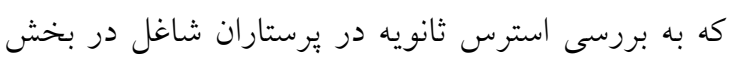

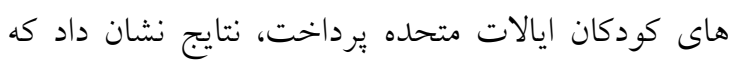

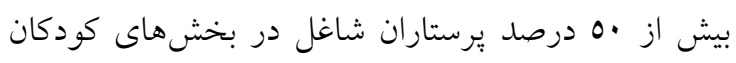

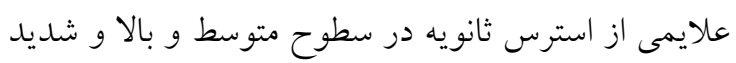

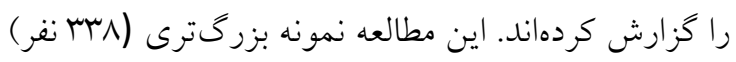

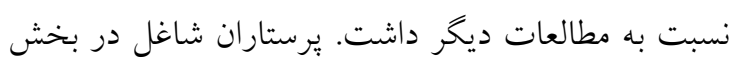

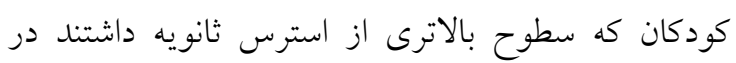

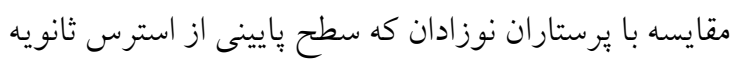

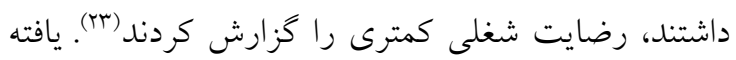
هاى يزوهش حاضر از برخى جهات با يافتهاى اين مطالعه

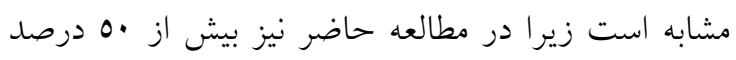

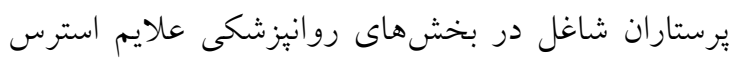

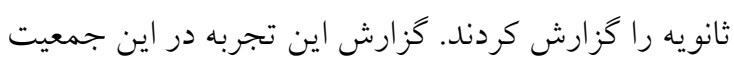

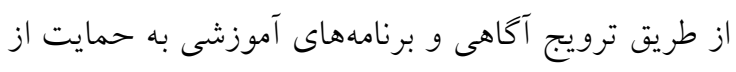

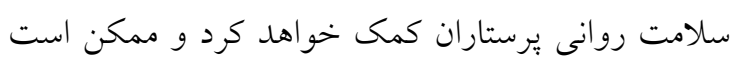
از ترى اين حرفه به علت استرس مربوط به كار جلو گيرى

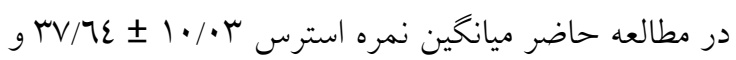

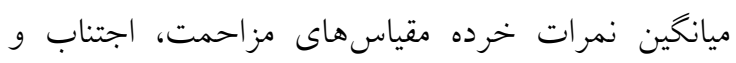

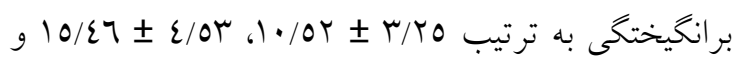

بحث و نتيجه كيرى نتايج حاصل از اين مطالعه نشان داد استرس ثانويه ناشى از آسيب يرستاران شركت كننده در اين تحقيق بين سطوح خفيف و متوسط قرار داشت. حدود نيمى از برستاران شاغل در بخش روانيزشكى در بالاى نقطه برش ابزار

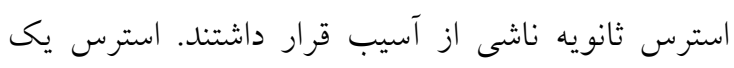

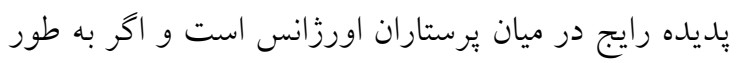

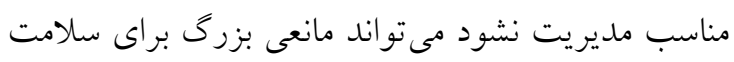

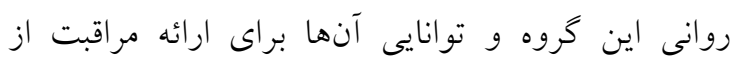

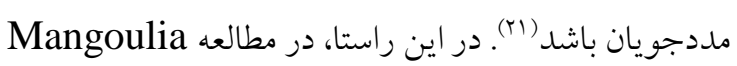
و همكاران در بخشهاى روانيزشكى يونان، اكثريت

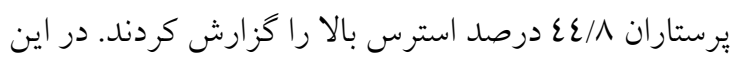

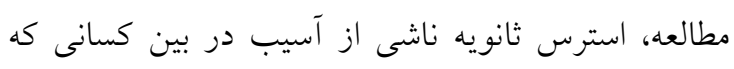
مايل بودند واحد روانيزشكى را ترى كنند بالاتر بود.

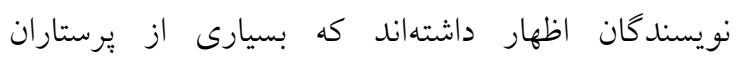

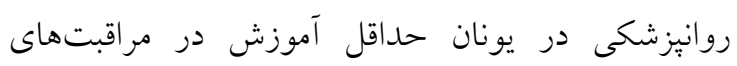

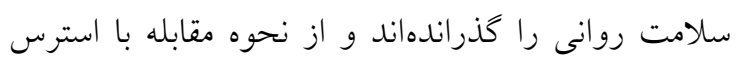
ثانويه ناشى از آسيب آحاهى كافى ندارند (Yr). هم:هنين

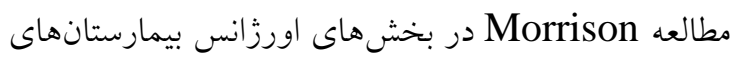

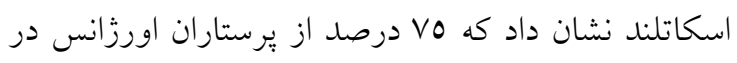
طول هفته كذشته حداقل يكى از علايم استرس ثانويه ناشى دانى 
ندارد (TV). در مطالعهى Mordeno و همكاران كه در بخش هاء هاى روانيزشكى فيلييين انجام شد، جديدترين مدلهاى

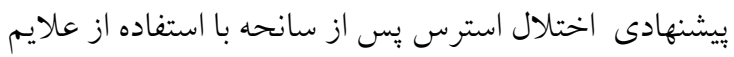

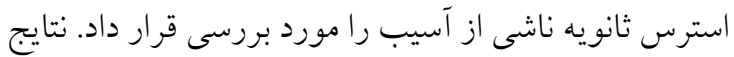

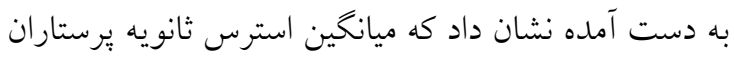

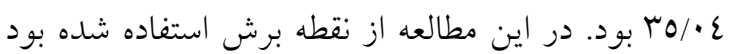

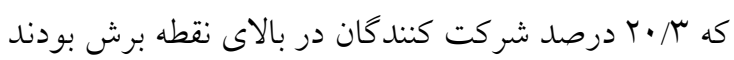

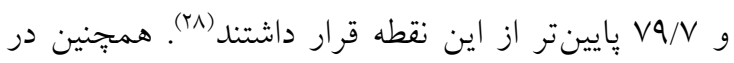

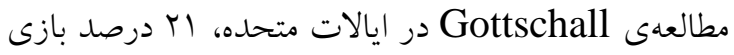
درمانخرها در بالاى نقطه برش قرار گرفتند و V9 درصد در

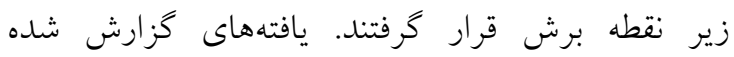

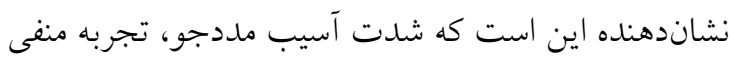
درمانكر و ساعات كارى تمام وقت سه عامل برتر بودند كه درمانخر را در معرض خطر بيشتر براى استرس ثانويه قرار

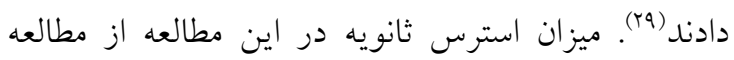

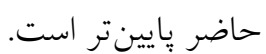

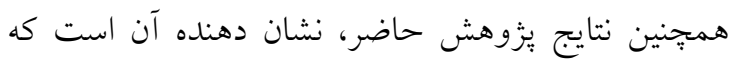
ميانخين نمره تاب آورى به دست آمده از ميانه نمره ابزار

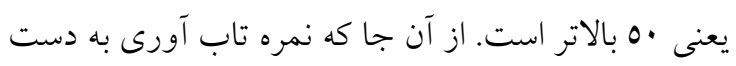

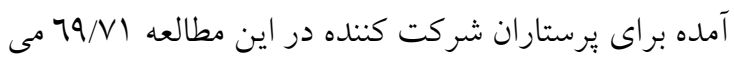

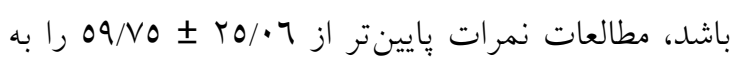

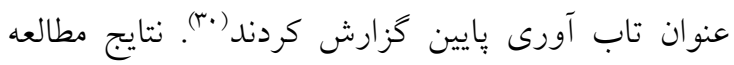
دهوان و همكارش نشان داد نمره تاب آورى در يرستاران شاغل در بخشهاى روانيزشكى

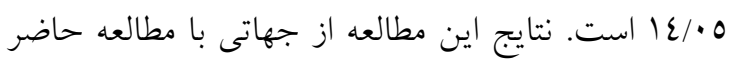

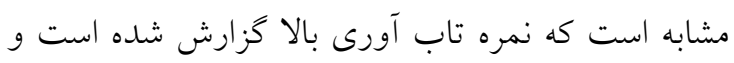

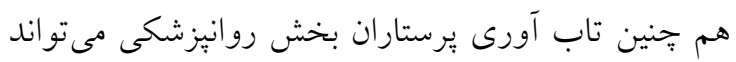

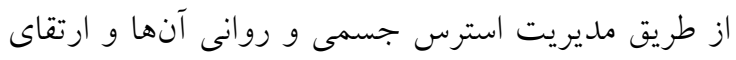

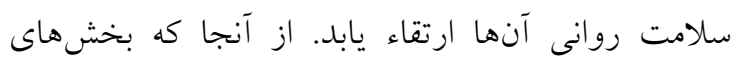

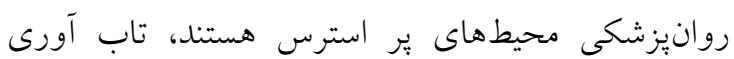

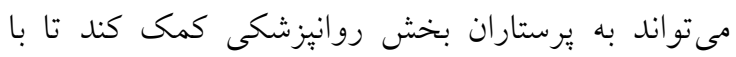
استرس شغلى خود كنار بيايند. اين مطالعه نشان داد كه به

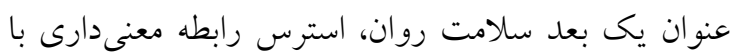

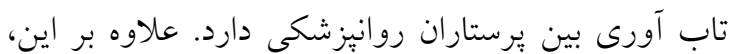

Kaladow ميانخين نمره $11 / 77 \pm$ ب بود. در مطالعهى

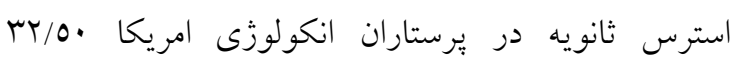

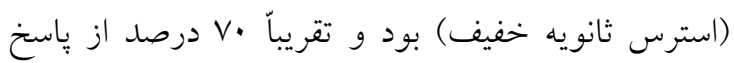
دهندكان در يايين نقطه برش ابزار قرار داشتند و نمرات

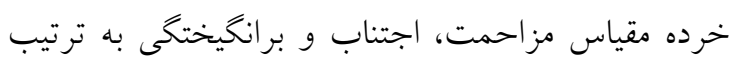

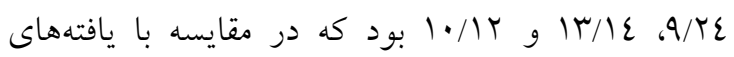

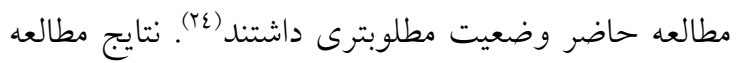

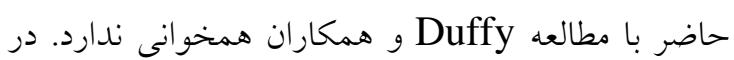

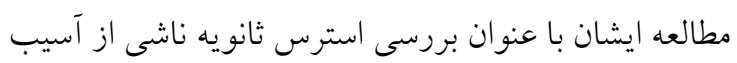

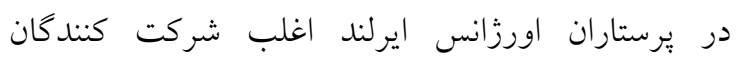
(\%/TV/T\&) وجود علايم استرس ثانويه را كزارش كردند.

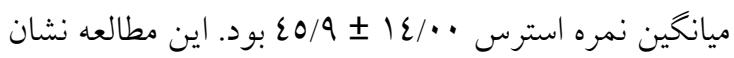
مى دهد كه برستاران شاغل در بخش هاى اورزانس در ايرلند

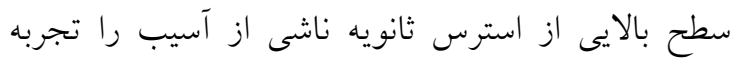

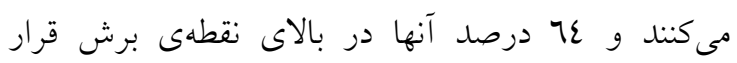

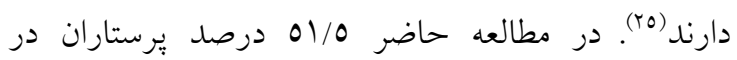
محدوده نقطه برش و بالاتر از آن قرار داشتند (• بـ/ بالاتراز

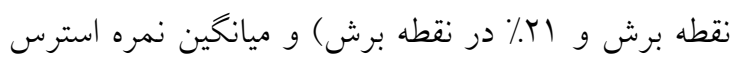

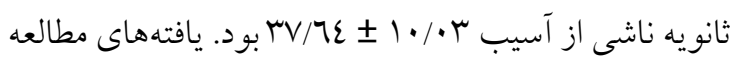

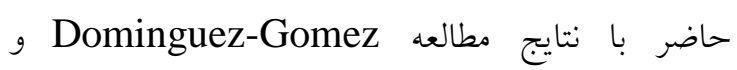
همكاران كه در بخش هاى اورزانس انجام شده بود همخوانى دارد. در مطالعهى آنها 10 درصد بران برستاران

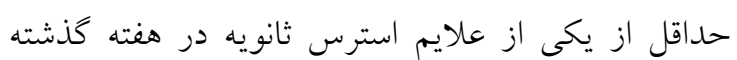

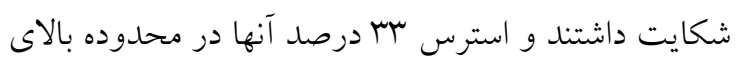

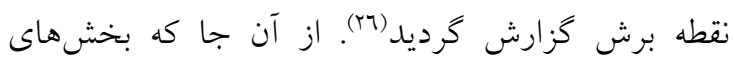
روانيزشكى داراى درجه بالايى از خشونت مددجويان

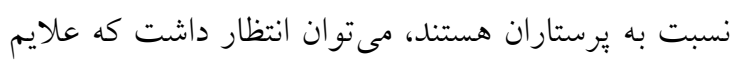

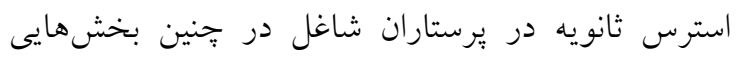

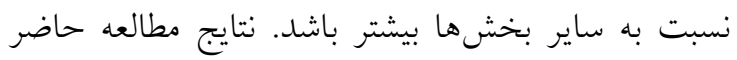

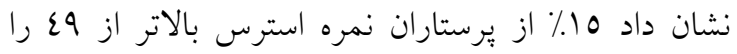
كسب كردهاند كه نشان دهنده استرس شديد مىباشد كه با فيا مطالعه Kintzle و همكاران كه بر روى مراقبين بهداشتى دردي

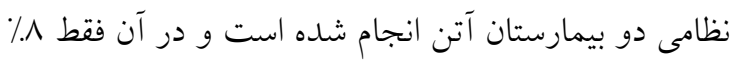

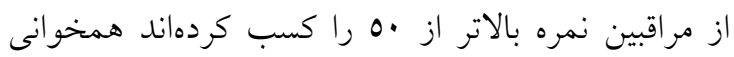


محدوديتهاى مطالعه حاضـــر مشــكل همكارى به دليل

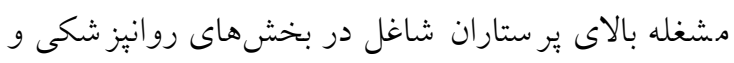

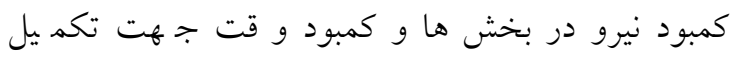

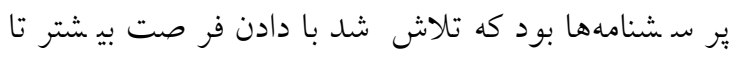

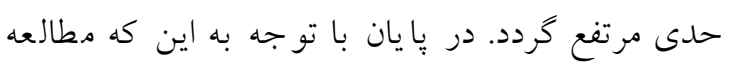

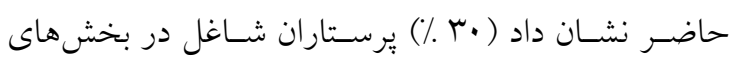

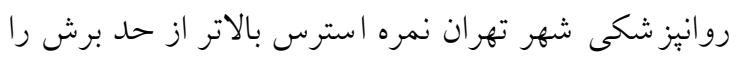
كســبـ كردهاند و همجينين با توجه به ارتباط معنى دار و

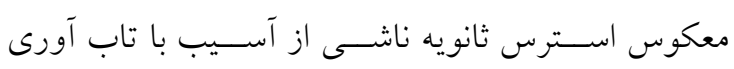

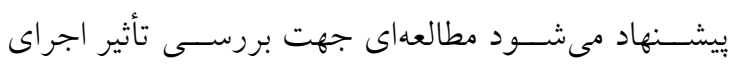

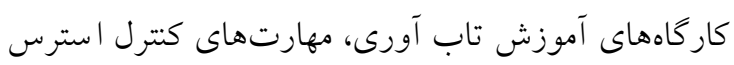

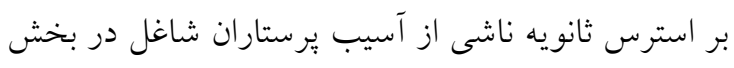

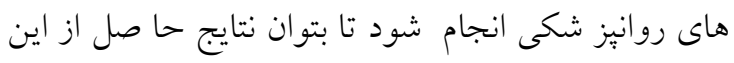

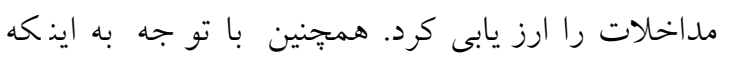

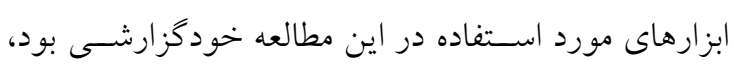

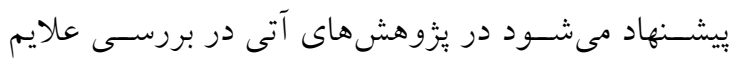

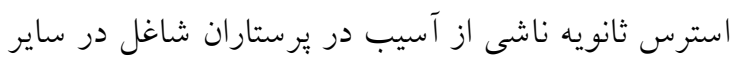

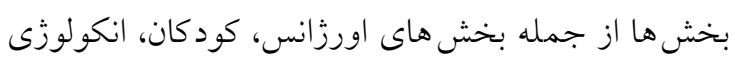

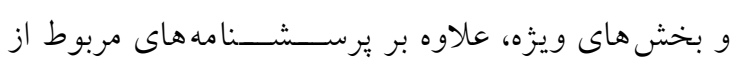

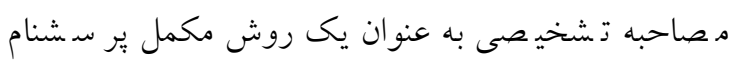

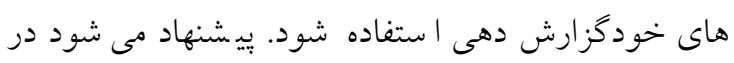

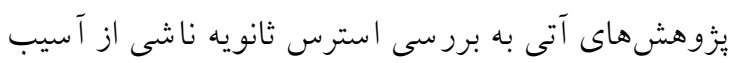

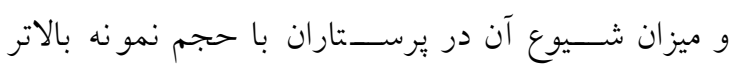
ير برداخته شود.

تعارض منافع: هيج گونه تعارض منافع توسط نويسندگان بيان نشده است

\section{تقدير و تشكر}

اين مقاله حاصل بايان نامه كارشناسى ارشد روان يرستارى

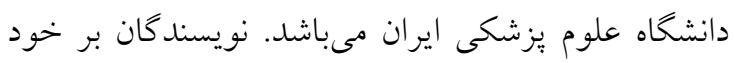

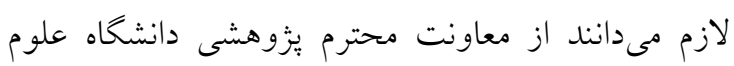

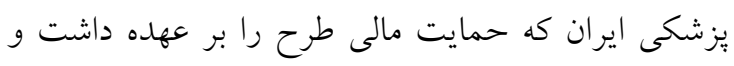

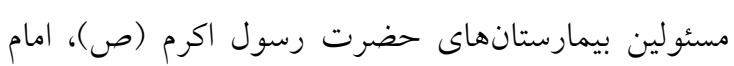

رابطه مثبت قابل توجهى بين سلامت روانى و تاب آورى

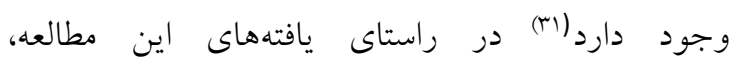
Hernandez

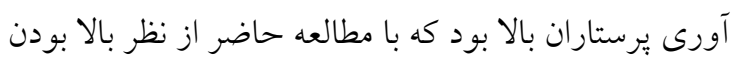

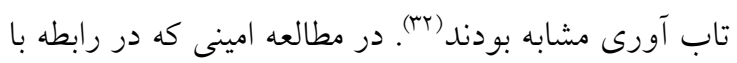
ارتباط تاب آورى و فرسودگى شغلى در شهر تهران انجام

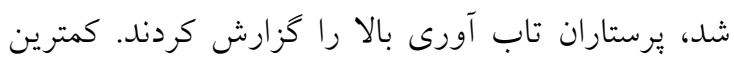

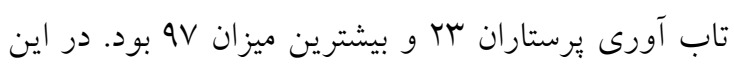

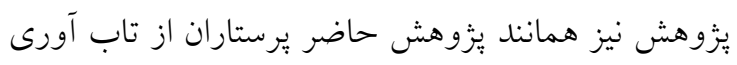
بالا برخوردار بودند. نتايج اين تحقيق نشان داد كه تاب تهني

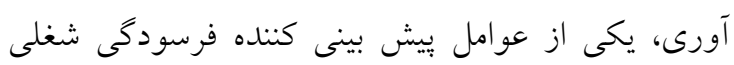

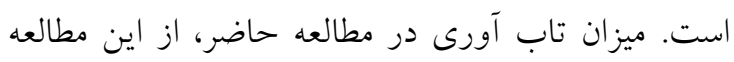

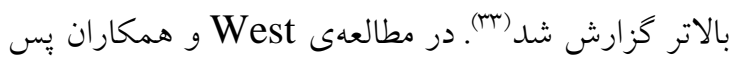

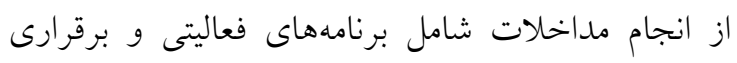

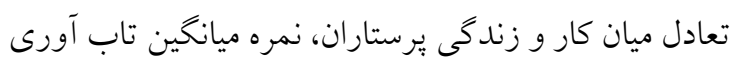

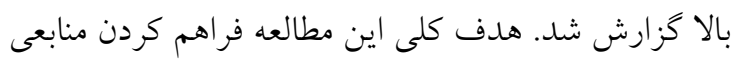

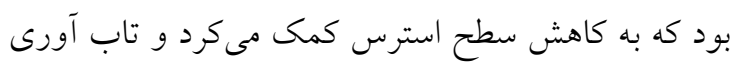
را افز ايش مى داد (عَ). نتايج مطالعه حاضر نشان دهنده آن است كه تاب آورى و و استرس ثانويه ناشى از آسيب ارتباط معنى دار آمارى دارند،

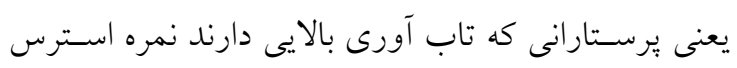

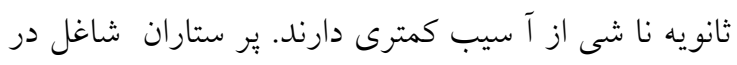

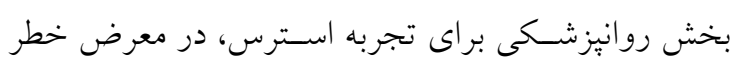

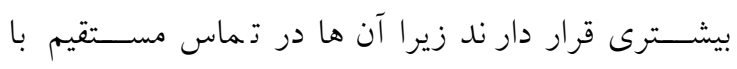
مددجو يان مبتلا به اختلالات روانى در محيط بســيار

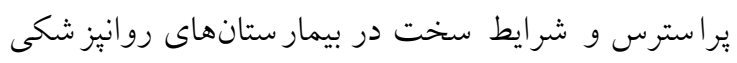

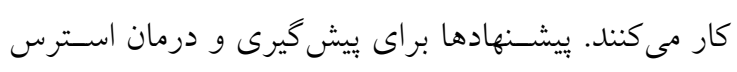

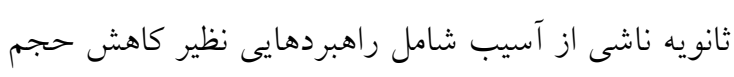
كار، افزايش نظارت بر كاركنان، بهبود بشــيـيانى كاركنان،

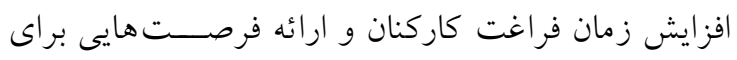
يرستار ان جهت دريافت خدمات سلامت روانى براى خود

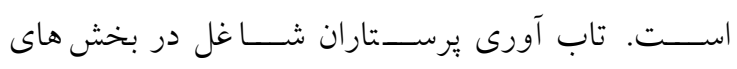

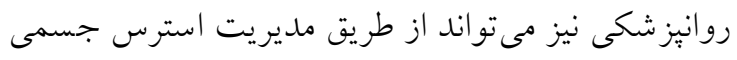

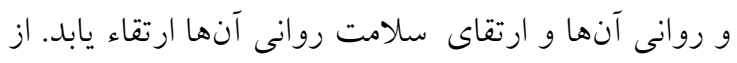




$$
\begin{aligned}
& \text { حسين(ع)، ايران و روزبه، يرستاران شركت كننده در اين }
\end{aligned}
$$

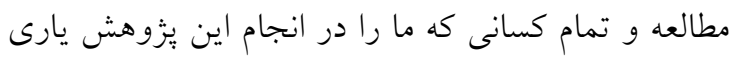

$$
\begin{aligned}
& \text { نمودند تشكر نمايند. }
\end{aligned}
$$

\section{References}

1. Whitebird RR, Asche SE, Thompson GL, Rossom R, Heinrich R. Stress, burnout, compassion fatigue, and mental health in hospice workers in Minnesota. J Palliat Med. 2013;16(12):1534-9.

2. Sharma J, Dhar RL, Tyagi A. Stress as a mediator between work-family conflict and psychological health among the nursing staff: Moderating role of emotional intelligence. Appl Nurs Res. 2016;30:268-75.

3. McGibbon E, Peter E, Gallop R. An institutional ethnography of nurses' stress. Qualitative Health Research. 2010;20(10):1353-78.

4. Melvin CS. Professional compassion fatigue: what is the true cost of nurses caring for the dying?. Int J Palliat Nurs. 2012;18(12):606-11.

5. Townsend SM, Campbell R. Organizational correlates of secondary traumatic stress and burnout among sexual assault nurse examiners. J Forensic Nurs. 2009;5(2):97-106.

6. Flarity K, Gentry JE, Mesnikoff N. The effectiveness of an educational program on preventing and treating compassion fatigue in emergency nurses. Adv Emergenc Nurs J. 2013;35(3):247-58.

7. Beck CT, Gable RK. A mixed methods study of secondary traumatic stress in labor and delivery nurses. J Obstet Gynecol\& Neonatal Nurs. 2012;41(6):747-60.

8. Yoo YS, Cho OH, Cha KS, Boo YJ. Factors influencing post-traumatic stress in Korean forensic science investigators. Asian Nurs Res. 2013;7(3):136-41.

9. Boyle DA. Countering compassion fatigue: A requisite nursing agenda. Online J Issues Nurs. 2011;16(1).

10. Beck CT, LoGiudice J, Gable RK. A mixed-methods study of secondary traumatic stress in certified nurse-midwives: shaken belief in the birth process. J Midwifery Women Health. 2015;60(1):16-23.

11. Geller JA, Madsen LH, Ohrenstein L. Secondary trauma: A team approach. Clin Soc Work J. 2004;32(4):415-30.

12. Ben-Porat A, Itzhaky H. Burnout among trauma social workers: The contribution of personal and environmental resources. J Soc Work. 2015;15(6):606-20.

13. Temitope K. Secondary traumatic stress, burnout and the role of resilience in New Zealand counsellors: a thesis presented in partial fulfilment of the requirements for the degree of Master of Arts in Psychology at Massey University, New Zealand (Doctoral dissertation, Massey University). 2014.

14. Chandler GE, Roberts SJ, Chiodo L. Resilience intervention for young adults with adverse childhood experiences. J Am Psychiatr Nurs Association. 2015;21(6):406-16.

15. Hart PL, Brannan JD, De Chesnay M. Resilience in nurses: An integrative review. Journal of Nursing Management. 2014;22(6):720-34.

16. Warelow P, Edward KL. Caring as a resilient practice in mental health nursing. Int J Ment Health Nurs. 2007;16(2):132-5.

17. Cameron F, Brownie S. Enhancing resilience in registered aged care nurses. Australas J Ageing. 2010;29(2):66-71.

18. Braithwaite M. Nurse burnout and stress in the NICU. Advances in neonatal care. 2008;8(6):3437.

19. Bride BE, Robinson MM, Yegidis B, Figley CR. Development and validation of the secondary traumatic stress scale. Research on social work practice. 2004;14(1):27-35.

20. Connor KM, Davidson JR. Development of a new resilience scale: The Connor-Davidson resilience scale (CD-RISC). Depression and anxiety. 2003;18(2):76-82.

21. Morrison LE, Joy JP. Secondary traumatic stress in the emergency department. J Adv Nurs. 2016;72(11):2894-906.

22. Mangoulia P, Koukia E, Alevizopoulos G, Fildissis G, Katostaras T. Prevalence of secondary traumatic stress among psychiatric nurses in Greece. Arch Psychiatr Nurs. 2015;29(5):333-8. 
23. Kellogg MB, Knight M, Dowling JS, Crawford SL. Secondary Traumatic Stress in Pediatric Nurses. J Pediatr Nurs. 2018;43:97-103.

24. Kaladow JK. Caring for the caregivers: Factors contributing to secondary traumatic stress in oncology nurses. Proquest, Umi Dissertatio; 2011.

25. Duffy E, Avalos G, Dowling M. Secondary traumatic stress among emergency nurses: a crosssectional study. Int Emerg Nurs. 2015;23(2):53-8.

26. Dominguez-Gomez E, Rutledge DN. Prevalence of secondary traumatic stress among emergency nurses. J Emerg Nurs. 2009;35(3):199-204.

27. Kintzle S, Yarvis JS, Bride BE. Secondary traumatic stress in military primary and mental health care providers. Military medicine. 2013;178(12):1310-5.

28. Mordeno IG, Go GP, Yangson-Serondo A. Examining the dimensional structure models of secondary traumatic stress based on DSM-5 symptoms. Asian J Psychiatr. 2017 ;25:154-60.

29. Gottschall JA. The Prevalence of Secondary Traumatic Stress Among Play Therapist. 2016.

30. Bagherinia H, Ildarabadi E, Bagherinia F. Relationship between personality traits and mental health with resilience mediation in nurses. Journal of Sabzevar University of Medical Sciences. 2016;22(6):1063-70. [Persian]

31. Dehvan F, Kamangar P, Baiezeedy S, Roshani D, Ghanei-Gheshlagh R. The relationship of mental health with resilience among psychiatric nurses. Nursing Practice Today. 2018 ;5(4):115. [Persian]

32. Hernandez SH, Morgan BJ, Parshall MB. Resilience, stress, stigma, and barriers to mental healthcare in US Air Force nursing personnel. Nursing research. 2016;65(6):481-6.

33. Amini F. The Relationship between Resiliency and Burnout in Nurses. Journal of Research Development in Nursing and Midwifery. 2013;11(2):94-102. [Persian]

34. West MM, Wantz D, Shalongo G, Campbell P, Berger K, Cole H, Seroskie D, Cellitti K. Evaluation of compassion and resilience in nurses: from evidence-based projects to research findings. Nursing and Palliative Care. 2017;2(4):1-7. 